\title{
Encefalopatia hereditária em bovinos no Estado do Espírito Santo ${ }^{1}$
}

\author{
Paulo V. Peixoto ${ }^{2 *}$, Bernardo M. Cunha ${ }^{3}$, Ticiana N. França ${ }^{4}$, Pedro S. Bezerra \\ Junior $^{5}$, Luís A.C. Brust ${ }^{3}$, Talitha M.F. Terra ${ }^{3}$ e Aníbal G. Armién ${ }^{6}$
}

\begin{abstract}
Peixoto P.V., Cunha B.M., França T.N., Bezerra Junior P.S., Brust L.A.C., Terra T.M.F \& Armién A.G. 2011. [Hereditary encephalopaty of cattle in Espírito Santo state, Brazil.] Encefalopatia hereditária em bovinos no Estado do Espírito Santo. Pesquisa Veterinária Brasileira 31(9):723-730. Departamento de Nutrição Animal e Pastagem, Instituto de Zootecnia, Universidade Federal Rural do Rio de Janeiro, Seropédica, RJ 23890-000, Brazil. E-mail: peixotop@ufrrj.br

The epidemiological, clinical and pathological aspects of a neurological disease have been described in cattle in the Ecoporanga county, northeastern Espírito Santo, Brazil. This disease of the central nervous system occurred only in daughters of a 5-year-old Nelore bull crossed with Nelore x Quianini cows. The clinical signs, which were detectable immediately or in the first weeks after birth, are characterized by ataxia, instability, circling, abnormal position of the limbs when standing or walking (removal and/or deviation of members from the normal position) and lateral deviation of the vertebral column (main axis of the body in diagonal). The disease is expressed by variable widths in their clinical manifestations. Most affected animals died due to incapacity of milk or food intake. The macroscopic examination shows variable degree of asymmetric sectorial depressed areas of the frontal and temporal telencephalic cortex, and in the cortex of the cerebellum, as well as correspondent muscular (appendicular) atrophy. Histological examination revealed that the depressed areas are due to the sectorial reduction of neuronal populations (probably atrophy/abiotrophy), mainly in the frontal and temporal brain lobes, and in the molecular and granular layers of the cerebellar cortex. Morphometric, immunohistochemical and ultrastructural studies are underway and should provide more information about the microscopical and pathogenetic aspects. Epidemiological data indicate that the illness is directly linked to the chromosome $\mathrm{X}$, with complete penetration and variable expressiveness.

INDEX TERMS: Hereditary encephalopaty, bovine, central nervous system, pathology.
\end{abstract}

RESUMO.- Descrevem-se os aspectos epidemiológicos e clínico-necroscópicos de uma doença neurológica hereditária observada em bovinos no município de Ecoporanga, norte do Estado do Espírito Santo. Trata-se de enfermidade do sistema nervoso central verificada exclusivamente em fêmeas, filhas de touro reprodutor de 5 anos de idade da raça Nelore,

\footnotetext{
${ }^{1}$ Recebido em 2 de março de 2011.

Aceito para publicação em 15 de julho de 2011.

${ }^{2}$ Departamento de Nutrição Animal e Pastagem, Instituto de Zootecnia, Universidade Federal Rural do Rio de Janeiro (UFRRJ), Seropédica, RJ 23890000, Brasil.*Autor para correspondência: peixotop@ufrrj.br

${ }^{3}$ Universidade Estácio de Sá, Estrada Boca do Mato 850, Vargem Pequena, RJ 22783-320, Brasil.

${ }^{4}$ Departamento de Epidemiologia e Saúde Pública, Instituto de Veterinária, UFRRJ, Seropédica, RJ.

${ }^{5}$ Departamento de Medicina Veterinária, Universidade Federal de Lavras (UFLA), Campus Universitário, Cx. Postal 37, Lavras, MG 37200-000, Brasil.

${ }^{6}$ Veterinary Diagnostic Laboratory, College of Veterinary Medicine, University of Minnesota, Saint Paul, MN 55108, USA.
}

oriundo do município de Curvelo, Minas Gerais, com vacas mestiças Nelore x Quianini; bezerros machos oriundos deste cruzamento não demonstraram quaisquer sinais relacionados à enfermidade. Os sinais clínicos, presentes ao nascimento ou detectáveis nas primeiras semanas de vida, caracterizamse por ataxia, perda do equilíbrio, instabilidade, andar em círculos, posicionamento incorreto dos membros no animal em estação ou em marcha (afastamento e/ou desvio de membros da posição normal) e desvio lateral da coluna (eixo principal do corpo em diagonal). De animal para animal, há marcada variação na intensidade das manifestações clínicas. Os bovinos mais afetados morrem devido à incapacidade de se alimentar. 0 exame macroscópico evidenciou, em grau variável de intensidade, áreas de depressão assimétrica setorial, sobretudo nos lobos frontal e temporal do córtex telencefálico e no córtex cerebelar. Em adição observou-se atrofia de grupos musculares de membros correspondentes às porções defeituosas no sistema nervoso central. 0 estudo histológico inicial revelou que as áreas deprimidas devem-se à re- 
dução setorial de populações neuronais (provavelmente abiotrofia/atrofia) principalmente nos lobos cerebrais frontal e temporal e nas camadas granular e molecular do córtex cerebelar. Estudos morfométrico, imunohistoquímico e ultraestrutural estão sendo realizados e devem trazer mais informações sobre os aspectos microscópicos e patogenéticos. Os achados epidemiológicos indicam que a enfermidade está diretamente ligada ao cromossoma X, com penetrância completa e expressividade variável.

TERMOS DE INDEXAÇÃO: Encefalopatia hereditária, bovino, sistema nervoso central, patologia.

\section{INTRODUÇÃo}

Malformações do SNC são distúrbios morfológicos congênitos (herdados ou adquiridos durante a gestação) (Noden \& De Lahunta 1990) comuns em animais domésticos, cuja variedade é talvez maior do que a que ocorre em outros tecidos (Maxie \& Youssef 2007). A rigor, não se conhece a exata frequência com que estes defeitos congênitos ocorrem nos animais domésticos (Noden \& De Lahunta 1990). Em bovinos, de acordo com Radostits et al. (2007), a incidência de anomalias congênitas, como um todo, está estimada entre $0,5 \%$ e $3 \%, 22 \%$ das quais localizadas no sistema nervoso central (SNC). Ainda em relação aos defeitos congênitos do sistema nervoso em bovinos descrevem-se taxas de prevalência mais elevadas, de até 1,8\% (Priester et al. 1970). No Rio Grande do Sul, a ocorrência de defeitos congênitos representou $0,88 \%$ de todos os materiais de bovinos recebidos no Laboratório Regional de Diagnóstico da UFPel entre 1978 e 2009 e, desse total, $18,75 \%$ eram malformações do sistema nervoso central (Marcolongo-Pereira et al. 2010).

Esses defeitos congênitos podem ser determinados por agentes infecciosos, distúrbios nutricionais ou, ainda, por plantas, agentes físicos (hipertermia em gestantes) ou químicos (Noden \& De Lahunta 1990, Schild 2001).

Os distúrbios congênitos hereditários são transmitidos por genes autossômicos dominantes e recessivos simples, genes dominantes incompletos (Noden \& De Lahunta 1990) ou ainda por genes ligados aos cromossomos sexuais (X-Linked) (Maxie \& Youssef 2007). A maioria das anomalias conhecidas deste grupo é transmitida por genes recessivos autossômicos, que resultam no nascimento de animais defeituosos, cujos progenitores são normais. Vale lembrar, ainda, que a expressão fenotípica de genes deletérios, sobretudo os de natureza autossômica recessiva, pode aumentar proporcionalmente em função do grau de consanguinidade dos animais (Priester et al. 1970, Schild 2001).

No que diz respeito às malformações que cursam com diminuição/perda do volume encefálico, isto é, condições enquadradas como atróficas ou hipoplásicas, por vezes, é muito difícil delimitar, com segurança, se enquadram-se em um ou em outro grupo. Adicionalmente, ocorrem as chamadas abiotrofias, condições especiais correlatas aos processos atróficos.

Segundo De Lahunta (1990), as abiotrofias do sistema nervoso central são enfermidades herdadas e refletem um erro estrutural intrínseco do metabolismo celular com precoce degenerescência do tecido nervoso, o que exclui todas as cau- sas exógenas que venham a determinar a morte celular prematura. Desse modo, todas as doenças congênitas degenerativas que tenham a herdabilidade confirmada deveriam ser chamadas de abiotróficas. Esse distúrbio cursa com deficiência neurológica manifesta nas primeiras semanas ou meses de vida (Maxie \& Youssef 2007), embora alguns animais possam apresentar sinais clínicos ao nascimento (De Lahunta 1990, Summers et al. 1995, De Lahunta \& Glass 2009). Apesar de processos abiotróficos do sistema nervoso central em animais poderem envolver múltiplas populações neuronais funcionalmente interrelacionadas, na maior parte das vezes, a lesão limita-se ao córtex cerebelar (De Lahunta 1990, Summers et al. 1995).

No que se refere à morfologia, em animais não foram encontrados registros de qualquer enfermidade similar à observada em bovinos no município de Ecoporanga, Estado do Espírito Santo. Em humanos, contudo, existe uma enfermidade do SNC classificada como neurodegenerativa e, que atualmente é considerada como uma desordem precoce do desenvolvimento cerebral que guarda algumas semelhanças com a moléstia de Ecoporanga. Trata-se da Síndrome de Rett, uma encefalopatia infantil crônica e progressiva que afeta, quase exclusivamente, crianças do sexo feminino. Nos casos clássicos, as manifestações clínicas são observadas nos primeiros meses de vida com comprometimento motor progressivo (Mahmood et al. 2010).

A detecção e o diagnóstico precoce dos problemas ligados à hereditariedade não só são fundamentais para que medidas profiláticas adequadas sejam tomadas, como também são importantes no desenvolvimento de modelos de estudo de enfermidades correlatas, geneticamente determinadas, no homem.

Esse estudo visa caracterizar epidemiologicamente uma enfermidade restrita a bovinos fêmeas descendentes de um touro Nelore PO no norte do Estado do Espírito Santo, determinar o quadro clínico, descrever as alterações macroscópicas e estabelecer algumas correlações entre os achados clínicos e as alterações morfológicas.

\section{MATERIAL E MÉTODOS}

\section{Animais}

Neste estudo cinco bezerras resultantes do cruzamento de um touro Nelore PO, de cinco anos de idade, com vacas mestiças Nelore x Quianini, foram avaliadas clínico-patologicamente.

\section{Histórico e estudo anamnéstico}

0 histórico e os dados anamnésticos referentes à enfermidade foram informados pelo proprietário e pelo médico veterinário responsável em duas visitas ao local onde ocorreu a enfermidade (Fazenda Jacutinga, município de Ecoporanga, ES).

Estudo clínico. Além dos sinais clínicos gerais foram avaliados o estado nutricional, aspectos comportamentais, frequências cardíaca e respiratória, temperatura e o aspecto das mucosas, fezes e urina. Através de exame neurológico acurado foram estudadas alterações correlacionadas a distúrbios sensitivos, motores e proprioceptivos, sobretudo perturbações referentes à consciência, ao comportamento em grupo e individual, à postura em estação, à deambulação (direção do movimento dos membros, bem como frequência, amplitude e força) e à apreensão de alimentos.

Estudo anátomo-patológico. As necropsias das Bezerras 3, 4 e 5 foram realizadas imediatamente após sedação (tiopental) e eutanásia (sulfato de magnésio), na própria Fazenda Jacutinga; ape- 
nas a Bezerra 1 foi examinada e necropsiada no Setor de Anatomia Patológica do Projeto Sanidade Animal Embrapa/UFRRJ. A Bezerra 2 foi examinada e necropsiada pelo médico veterinário responsável da fazenda.

Fragmentos de pele e anexos cutâneos, língua, tonsilas palatinas, parótidas, olhos, esôfago, traquéia, tireóide, linfonodos, pulmão, coração, timo (quando presente), junção costo-condral, medula óssea, músculo diafragma, músculo estriado esquelético, estômago, intestino delgado (duodeno, jejuno, íleo), intestino grosso (ceco, cólon, reto), baço, fígado, rim, adrenal e bexiga foram coletados e fixados em formol a $10 \%$, à exceção do cérebro, cerebelo, hipófise, medula espinhal e nervos periféricos que foram fixados em formol a $20 \%$.

\section{RESULTADOS}

\section{Histórico e epidemiologia}

Na propriedade de aproximadamente 800 hectares, situada no município de Ecoporanga, norte do Estado do Espírito Santo, existiam, à época dos primeiros casos, um total de 1300 bovinos, dentre os quais 500 matrizes (mestiças Nelore x Quianini) e 12 touros Nelore PO, criados em regime semi-extensivo, com rotação de pastagens em Brachiaria decumbens e B. brizhanta. Em 1999 ocorreram os primeiros casos de uma enfermidade marcada por alterações clínico-patológicas de ordem neurológica que afetava apenas fêmeas, resultantes do cruzamento de um touro nelore PO, que fora introduzido no rebanho na estação de monta anterior, com vacas mestiças Nelore x Quianini. Foram constatadas 35 fêmeas enfermas, 25 com sinais clínicos acentuados. Todos os machos filhos desse touro eram normais. Esse touro, de 5 anos de idade, foi adquirido em uma fazenda do município de Curvelo, MG. Os animais afetados e não afetados eram vacinados para raiva, brucelose, clostridiose e febre aftosa, se alimentavam da mesma pastagem, recebiam suplementação mineral, e eram submetidos a manejo semelhante.

\section{Sinais clínicos}

Os sinais clínicos da enfermidade (Quadro 1), em geral verificados logo após o nascimento ou nas primeiras semanas de vida, variaram na intensidade. Muitas bezerras, porém, apresentaram sinais neurológicos mais evidentes à me- dida que foram se desenvolvendo, principalmente, entre 2 e 6 meses de idade. Algumas bezerras recém-nascidas (assistidas) demoraram até cinco dias para levantar-se com auxílio, enquanto outras morriam por absoluta incapacidade de manterem-se em pé e/ou sugar o leite.

A enfermidade, em geral, cursava com evolução crônica e muitas fêmeas morreram após acidentes (afogamento, quedas em valas, enforcamentos) ou foram eutanasiadas por estarem muito debilitadas. Algumas fêmeas recém-nascidas tiveram sinais clínicos muito discretos.

As bezerras mais afetadas encontravam-se em precária condição corporal, algumas apáticas, com dificuldade na locomoção, sujeitas a constantes quedas, permanecendo por prolongados períodos em decúbito esternal. Verificou-se dificuldade de mamar (leite escorria pelas comissuras labiais) que, mais tarde, evoluía para dificuldade de apreensão e mastigação, com acúmulo de alimentos na cavidade oral e salivação excessiva. Adicionalmente foram observados incoordenação motora (ataxia), instabilidade, perda de equilíbrio, andar em círculo, estação com os membros afastados, abertura lateral de um dos membros anteriores, sustentação do corpo em diagonal com curvatura da medula espinhal (apoio em membros contra-laterais), desvio da cauda (Fig.1-3) e dificuldade para se levantar. Constatou-se, também, variável e proporcional atrofia dos músculos (quadríceps femoral, semitendináceo, semi-membranáceo, da musculatura da garupa e da escápula), acompanhada por redução na amplitude das respostas dos reflexos dos boletos, de tropeço e dos tendões, verificados sob ação estimulatória, que contribuíam para a dificuldade na deambulação e perpetuação da postura errática. As fêmeas , ao serem excitadas ou movimentadas, apresentavam agravamento do quadro clínico, aparentemente pela exigência de movimentação repentina.

Depois de instalados, em geral, os sinais clínicos persistiam, embora alguns animais tenham-se adaptado parcialmente e conseguido condições de deambulação; em muitos outros, os sinais clínicos pioravam. Não obstante, as bezerras permaneciam integradas ao rebanho; esses animais, na dependência de maior ou menor comprometimento neurológico,

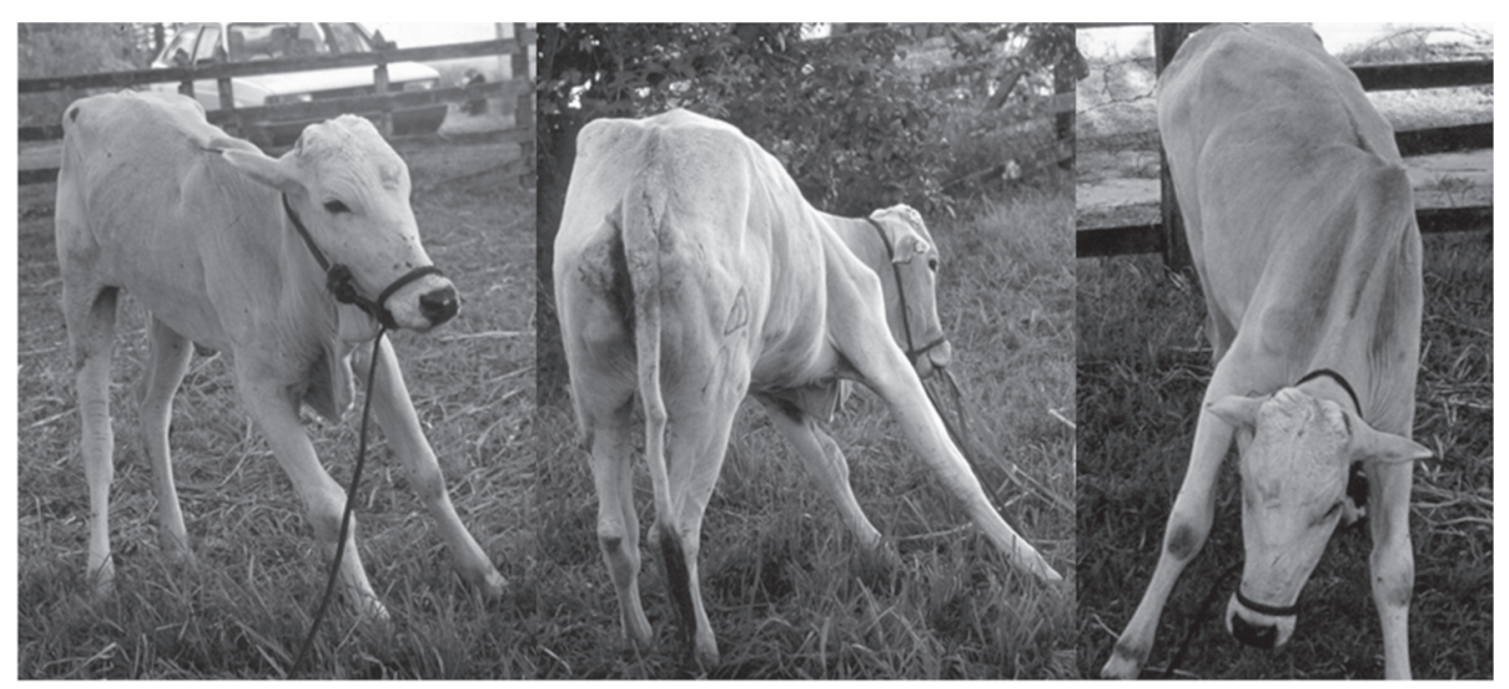

Fig.1. Aspecto típico do bezerro mais afetado pela Doença de Ecoporanga, em estação com postura assimétrica, desvio lateral da coluna vertebral, apoio nos membros contra-laterais e leve desvio da cauda (Bezerro 1). 


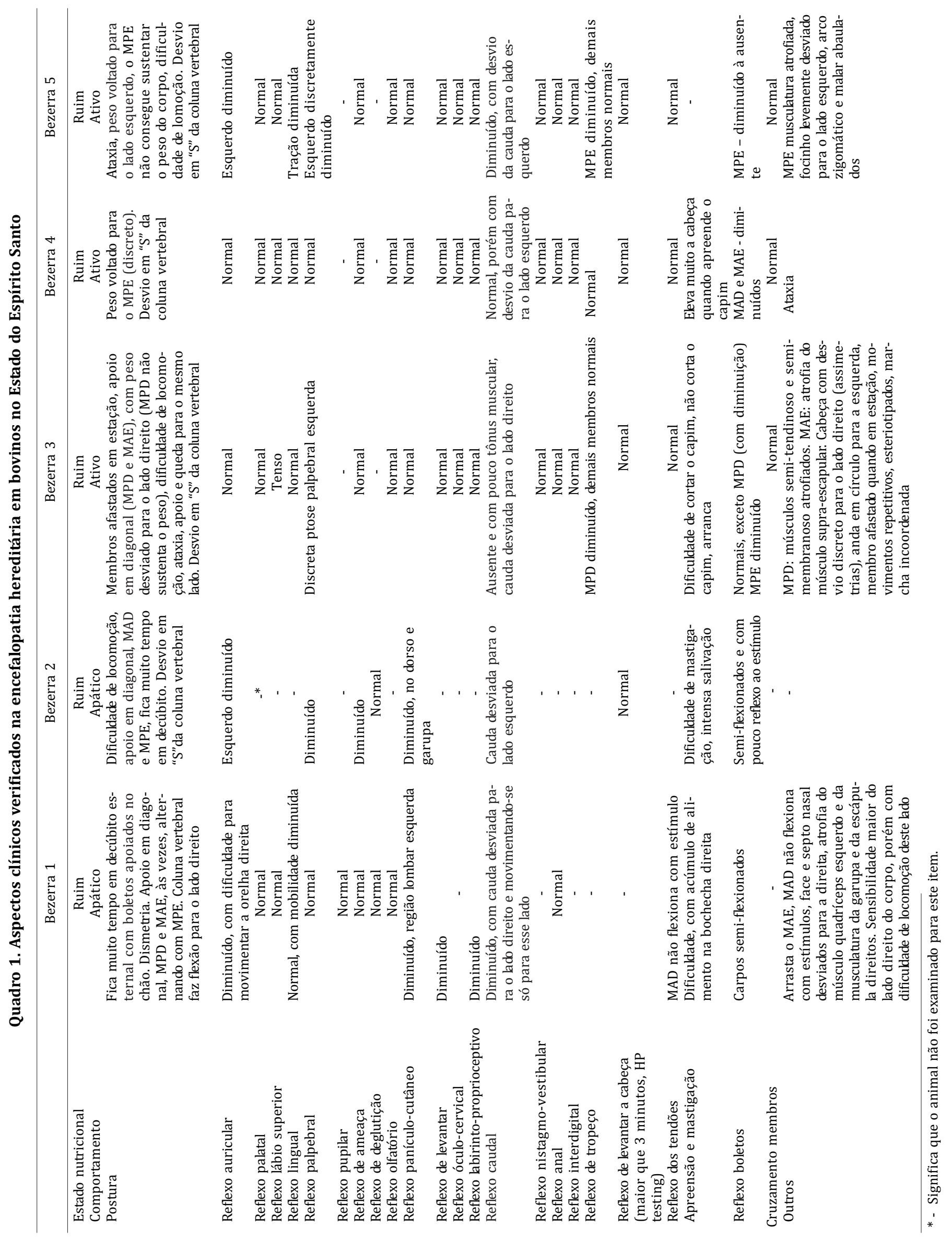




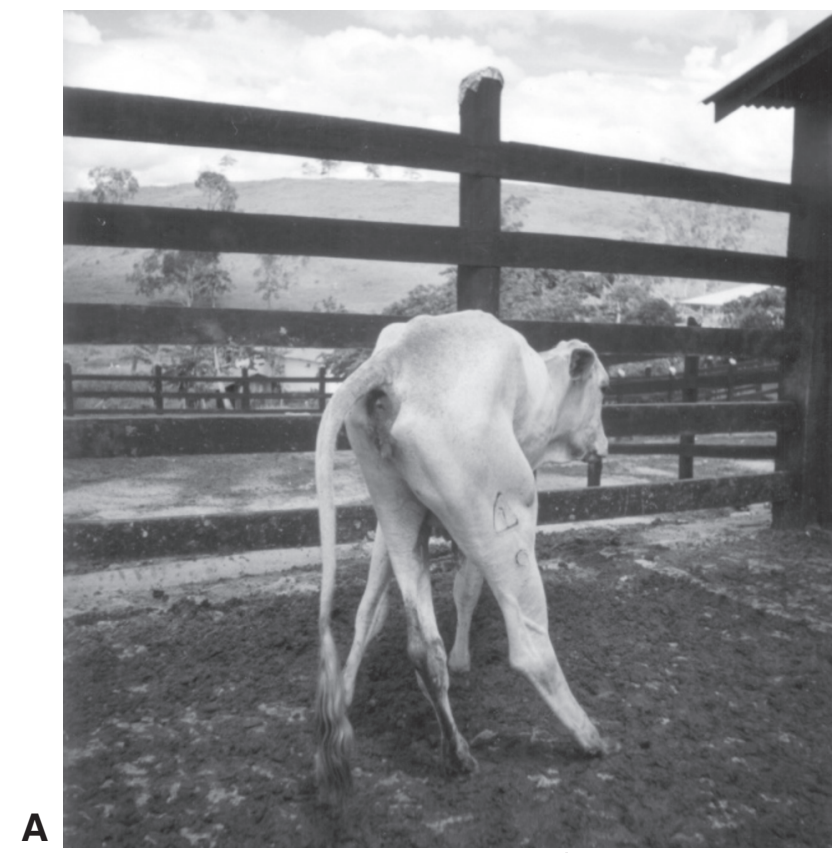

Fig.2. (A) Bezerra 2 e (B) Bezerra 3, em posição típica da Doença de Ecoporanga.

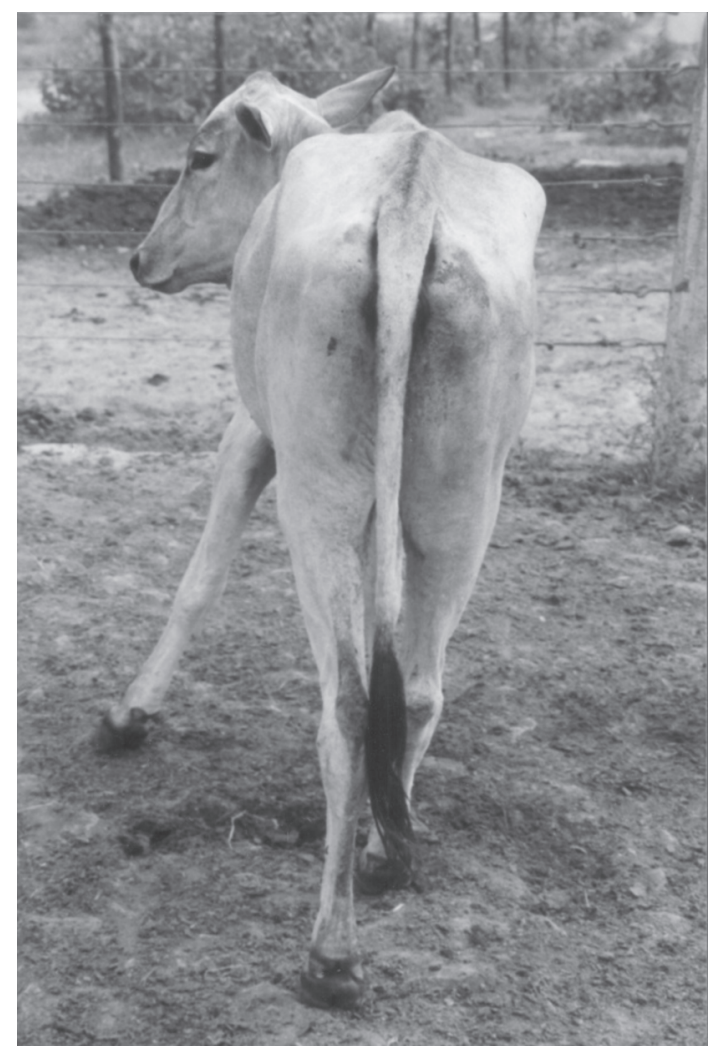

Fig.3. Bezerra 5. Postura típica da Doença de Ecoporanga.

apresentavam-se em diferentes estágios de nutrição correspondente à dificuldade de estabilização postural e apreensão dos alimentos.

Pelo menos sete fêmeas doentes foram vendidas para corte. As novilhas tinham crescimento, ganho de peso e desenvolvimento reprodutivo deficitários. Apenas três fêmeas apresentaram cio, porém não foi permitido que fossem cobertas.

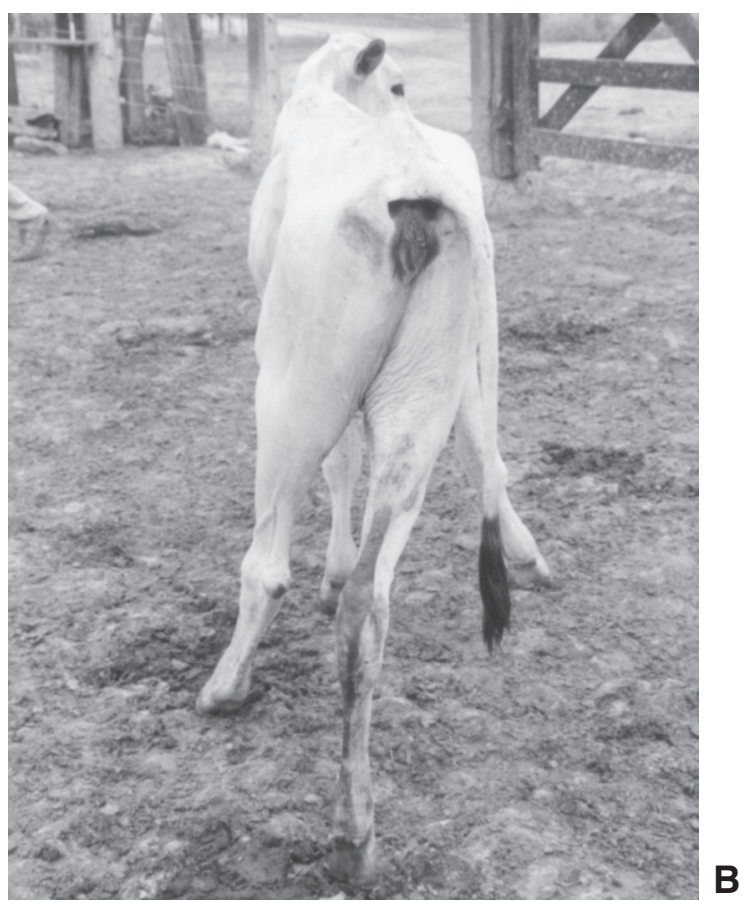

\section{Achados morfológicos}

Nos animais mais afetados o encéfalo era menor como um todo, o que ficava evidenciado pelo "excesso de meninges" (Fig.4). Por vezes o hemisfério telencefálico esquerdo era maior que o direito e vice-versa (hemimicrocefalia) (Fig.4). Havia áreas de depressão em variável grau de intensidade (Fig.4) mais evidentes na superfície dos lobos frontal, parietal e temporal do córtex encefálico. Essas áreas deprimidas eram representadas por marcada redução na altura dos giros (circunvoluções cerebrais), ou agiria focal, com consequente redução na profundidade de sulcos adjacentes. No cerebelo de parte dos animais, áreas atróficas assimétricas nas folhas eram facilmente perceptíveis.

Histologicamente havia ausência setorial de neurônios corticais sobretudo dos lobos temporal e frontal do cérebro e nas folhas cerebelares (camadas molecular e granular).

\section{DISCUSSÃO}

A natureza da enfermidade em estudo e sua classificação entre as malformações do SNC merece considerações. A questão que se apresenta, inicialmente, é: trata-se de processo hipoplásico ou atrófico/abiotrófico? Os processos abiotróficos caracterizam-se pela senescência prematura e/ou degeneração de uma população de neurônios já formada, em consequência de um defeito metabólico intrínseco (Summers et al. 1995), o que implica no aparecimento de manifestações clínicas nas primeiras semanas ou meses de vida ou, excepcionalmente, ao nascimento (De Lahunta 1990, Summers et al. 1995, De Lahunta \& Glass 2009), em geral, com curso progressivo. Já os processos hipoplásicos do SNC (secundários à influência de fatores intrínsecos e/ou extrínsecos, tais como desordens hereditárias, desequilíbrios nutricionais, ação de agentes teratogênicos e infecções víricas), em geral, cursam com degeneração/necrose das populações de células germinativas e desenvolvimento incompleto do sistema nervoso 

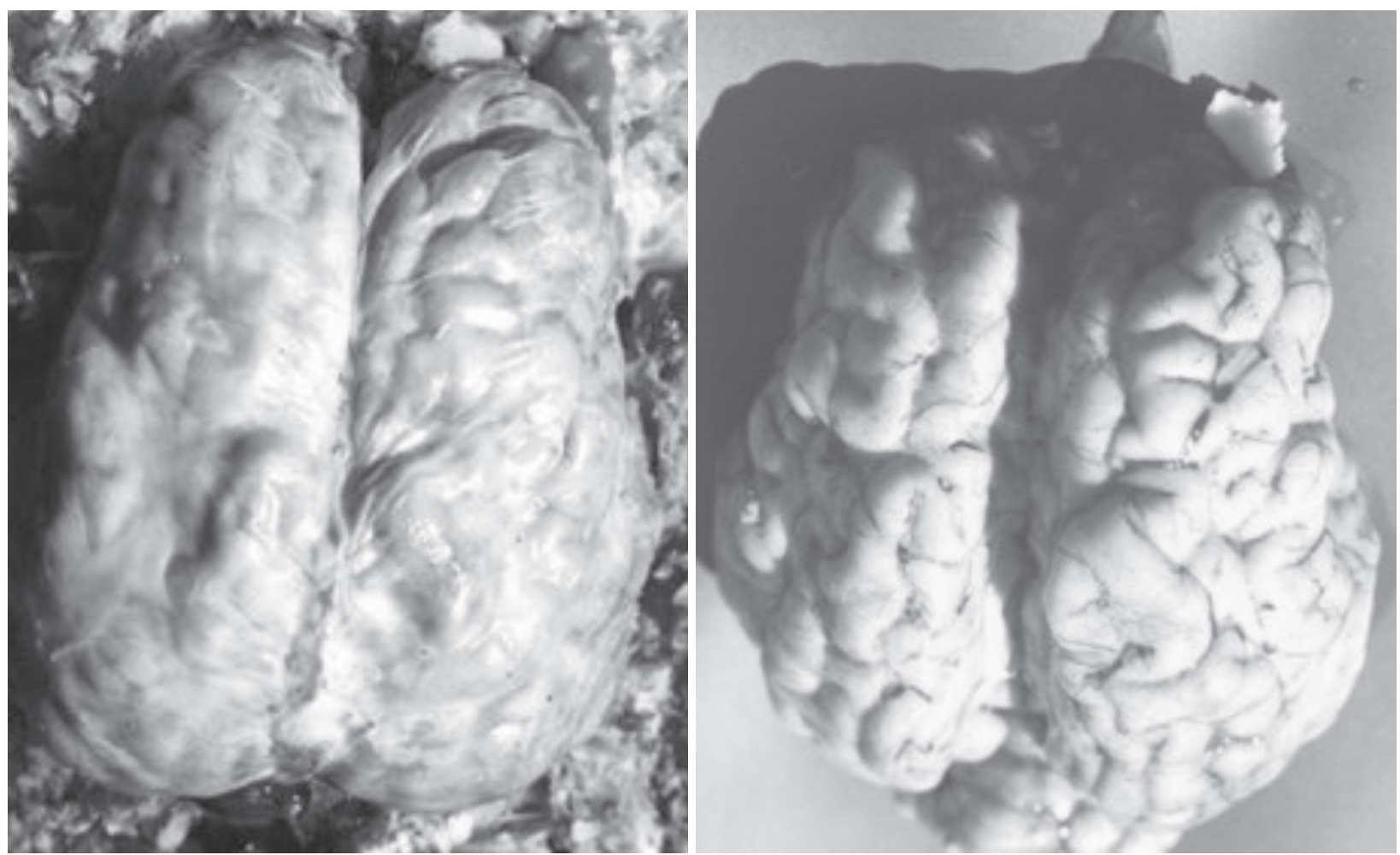

Fig.4. (A) Encéfalo da Bezerra 1, recoberto por meninges evidenciando hemimicroencefalia esquerda com áreas de depressão, e (B) sem meninges com marcada depressão em áreas dos lobos temporal.

central (Summers et al. 1995). Por vezes, os fatores desencadeantes do processo hipoplásico também podem levar à morte de populações de células já plenamente desenvolvidas e estabelecer concomitante processo atrófico (Summers et al. 1995). Segundo Maxie \& Youssef (2007), a diferenciação entre processo abiotrófico/atrófico e hipoplásico não é bem delimitada, uma vez que as alterações inerentes a cada uma destas entidades podem se sobrepor.

Não resta dúvida que a Doença de Ecoporanga (DE) se enquadra no grupo de encefalopatias atróficas/abiotróficas ou hipoplásicas, porém estabelecer com exatidão a qual dos dois grupos pertence, pelo menos por enquanto, é difícil. Para tanto, serão necessários estudos morfométricos e imuno-histoquímicos das áreas alteradas do sistema nervoso central, bem como a realização de estudos genéticos dos animais afetados por essa enfermidade. Contudo, o achado de microcefalia ou hemimicrocefalia, acompanhado de "excesso de meninges" indica, mais provavelmente, que houve processo atrófico/ abiotrófico.

De acordo com Riet-Correa et al. (1998) processos abiotróficos não cursariam com lesões macroscópicas, apenas os processos hipoplásicos.

Os aspectos epidemiológicos e clínico-necroscópicos, peculiares à DE, não apresentam maiores semelhanças com os de quaisquer outras malformações do sistema nervoso central previamente descritas em animais.

Assim, o levantamento epidemiológico deixa claro que trata-se de uma doença neurológica hereditária, transmitida provavelmente por gene ligado ao cromossoma X paterno, já que apenas as descendentes fêmeas oriundas do cruzamento de um touro reprodutor Nelore PO com diversas vacas mestiças Nelore x Quianini, desenvolveram a enfermidade. As circunstâncias epidemiológicas que cercam a ocorrência de todas as anomalias congênitas do SNC de bovinos, aparentemente diferem das da doença dos bovinos de Ecoporanga. Em geral, cerca de 50\% dos animais portadores de malformações do sistema nervoso central são natimortos (Radostits et al. 2007) e, caso venham a termo, sobrevivem por poucas horas ou dias (Summers et al. 1995), enquanto que os bovinos afetados pela DE apresentavam, em geral, curso clínico crônico. Alterações dessa natureza podem ser condicionadas por uma gama de agentes (vírus, plantas tóxicas, fatores nutricionais, hereditariedade, administração de medicamentos e, mesmo, consanguinidade) (Radostits et al. 2007) que, contudo, determinam padrões de ocorrência/incidência muito diferentes daqueles observados na enfermidade em estudo.

A penetrância completa (todas as fêmeas, filhas do touro, apresentaram algum grau de déficit neurológico), associada à expressividade variável do gene mutante, também é peculiar. Inicialmente pensamos que se tratava de uma enfermidade sempre progressiva, o que é incorreto. Nos casos de menor grau de comprometimento na morfologia do SNC, os animais desenvolveram certa capacidade de compensação, de tal forma que alguns deles, com o tempo, apresentavam melhora de deambulação e apreensão de alimentos, embora, de forma geral, a enfermidade ainda pudesse ser notada pela postura atípica. Ainda hoje vem sendo mantida viva, para estudos genéticos, uma vaca enferma, que nasceu em 2000, filha do touro-problema.

Dentre as malformações do SNC descritas em bovinos, a que mais se aproxima das alterações morfológicas verifica- 
das no sistema nervoso central dos bovinos acometidos pela DE é a hipoplasia prosencefálica. Esta alteração caracterizase por variáveis graus de malformação no diencéfalo, mesencéfalo, metencéfalo, mielencéfalo associadas à ausência das porções telencefálicas (Summers et al. 1995), porém não cursa, como o próprio nome diz, com lesão cerebelar.

Hipoplasia cerebelar congênita hereditária, abiotrofia cerebelar, atrofia cortical cerebelar, convulsão familiar e ataxia e hipermetria congênita, cursam com ataxia e instabilidade (Schild et al. 1993, 2001, Summers et al. 1995, De Lahunta \& Glass 2009), sinais que fazem parte do quadro clínico das bezerras acometidas pela DE, contudo a postura atípica em estação verificada na DE difere bastante da postura eventualmente manifesta, em casos de doenças primárias do cerebelo (à estação, o animal permanece em base ampla com ataxia do tronco, ou seja, oscilação do tronco para todas as direções) (Radostits et al. 2007). Além disso, a morfologia das alterações cerebelares também é diversa. Outras doenças do sistema nervoso que ocorrem na fase inicial da vida, como deficiências de cobre, de vitamina A, de iodo, e de manganês (Underwood \& Suttle 1999) ou doenças do armazenamento lisossomal, induzidas por planta ou hereditárias não determinam lesões comparáveis às observadas na DE. Plantas como Sida carpinifolia (Pedroso et al. 2010), Swainsona sp. (Laws \& Anson 1968), Astragalus sp. (Molyneux \& James 1982), Oxytropis sp. (Stegelmeier et al. 1999), Solanum fastigiatum var. fastigiatum (Rech et al. 2006), Ipomoea fistulosa (Tokarnia et al. 1960, Antoniassi et al. 2007), Veratrum californicum (Binns et al. 1963), Lupinus sp. e Conium maculatum (López et al. 1999), que afetam o sistema nervoso, foram descartadas após visita na propriedade e, também, de qualquer maneira, não intoxicariam somente as fêmeas.

Algumas das manifestações clínicas observadas em moléstias do neurônio motor inferior em animais e humanos como fraqueza muscular, hiporreflexia, hipotonia ou atonia e atrofia muscular neurogênica (De Lahunta \& Glass 2009), também estiveram presentes nos animais afetados pela DE. Esses distúrbios caracterizam-se por quadro clínico súbito de astenia muscular com evolução para tetraplegia nas primeiras semanas de vida (Summers et al. 1995), enquanto que a DE tem curso crônico, que, em geral, se inicia ao nascimento ou nos primeiros dias de vida, sem perda total da capacidade deambulatória, ou arreflexia como observado nas fases finais das doenças do neurônio motor inferior (Summers et al. 1995), além de não ser progressiva.

As infecções pelos vírus da BVD (Dones et al. 1980) e da Língua Azul (Barnard \& Pienaar 1976) podem induzir a malformações dos SNC de bovinos recém-nascidos, contudo, também nesses casos, as lesões não são similares, além de, por serem de origem viral, não apresentarem predisposição sexual.

Através de comparação com as malformações que afetam o sistema nervoso central de seres humanos foram verificadas algumas semelhanças epidemiológicas e clínico-patológicas com a Síndrome de Rett. Tanto a DE, quanto a forma clássica da Síndrome de Rett (Mahmood et al. 2010), só ocorrem em fêmeas. Clinicamente, as duas enfermidades cursam com desordem neurológica crônica, acompanhada de anormalidades posturais com desvio da coluna vertebral. À ne- cropsia de indivíduos acometidos por essas duas condições revela similaridades, entre elas microcefalia com perda de tecido nervoso nas áreas do córtex frontal e núcleo caudado, no caso da Síndrome de Rett e defecção setorial de populações neuronais em especial nos lobos frontal e temporal do córtex, mas também em folhas do cerebelo no caso de animais afetados pela DE.

O proprietário eutanasiou o touro responsável pela transmissão do gene e estudos genéticos com esse animal não puderam ser realizados. De qualquer forma, estudos genéticos através de cruzamentos consaguíneos, com o objetivo de verificar como o distúrbio se transmite, estão sendo realizados em duas filhas deste touro.

Agradecimentos.- A Dra. Ana Lucia Schild pelas sugestões/correções. Ao Conselho Nacional de Desenvolvimento Científico e Tecnológico (CNPq) pelo suporte financeiro. P.V. Peixoto é bolsista de produtividade do CNPq.

\section{REFERÊNCIAS}

Antoniassi N.A.B., Ferreira E.V., Santos C.E.P., Campos J.L.E., Nakazato L. \& Colodel E.M. 2007. Intoxicação espontânea por Ipomoea carnea subsp. fistulosa (Convolvulaceae) em bovinos no Pantanal Matogrossense. Pesq. Vet. Bras. 27(10):415-418.

Barnard B.J.H \& Pienaar J.G. 1976. Bluetongue virus as a cause of hydranencephaly in cattle. Onderstepoort J. Vet. Res. 43(3):155-158.

Binns W., James L.F., Sheipe J.L. \& Everett G. 1963. A congenital cyclopiantype malformation in lambs induced by maternal ingestion of a range plant, Veratrum californicum. Am. J. Vet. Res. 24:1164-1175.

De Lahunta A. 1990. Abiotrophy in animals: A review. Am. J. Vet. Res. 54:6576.

De Lahunta A. \& Glass E. 2009. Veterinary Neuroanatomy and Clinical Neurology. $3^{\text {rd }}$ ed. Saunders Elsevier, Philadelphia. 540p.

Dones J.T., Terlecki S., Richardson C., Harkness J.W., Sands S.S., Patterson D.S., Sweasey D., Shaw I.G., Winkler C.E. \& Duffell S.J. 1980. Bovine virus diarrhea-mucosal disease virus: Pathogenicity for the fetal calf following maternal infection. Vet. Rec. 106(23):473-479.

Laws L. \& Anson R.B. 1968. Neuronopathy in sheep fed Swainsona luteola and S. galegifolia. Aust. Vet. J. 44(10):447-452.

López T.A., Cid M.S. \& Bianchini M.L. 1999. Biochemistry of hemlock (Conium maculatum L.) alkaloids and their acute and chronic toxicity in livestock: A review. Toxicon 37(6):841-865.

Mahmood A., Bibat G., Zhan A.L., Izbudak I., Farage L., Horska A., Mori S. \& Naidu S. 2010. White Matter Impairment in Rett Syndrome: Diffusion Tensor Imaging Study with Clinical Correlations. Am. J. Neuroradiol. 31:295-299.

Maxie M.G. \& Youssef S. 2007. Nervous system, p.298-322. In: Maxie M.G. (Ed), Jubb, Kennedy and Palmer's Pathology of Domestic Animals. Vol.1. $5^{\text {th }}$ ed. Saunders Elsevier, Philadelphia. 1229p.

Molyneux R.J. \& James L.F. 1982. Loco intoxication: Indolizidine alkaloids of spotted locoweed (Astragalus lentiginosus). Science 216:190-191.

Noden D.M. \& De Lahunta A. 1990. Embriologia de los animales domesticos. Acribia, Zaragoza. 399p.

Pedroso P.M.O., Oliveira L.G.S., Cruz C.E.F., Soares M.P., Barreto L.R.B. \& Driemeier D. 2010. Doença do armazenamento lisossomal induzida pelo consumo de Sida carpinifolia em bovinos do Rio Grande do Sul. Pesq. Vet. Bras. 30(10):816-826.

Priester W.A., Glass A.G. \& Waggoner N.S. 1970. Congenital defects in domesticated animals: General considerations. Am. J. Vet. Res. 31:18711879.

Radostits O.M., Gay C.C., Hinchcliff K.W. \& Constable P.D. 2007. Veterinary Medicine: A textbook of the diseases of cattle, horses, sheep, pigs, and goats. $10^{\text {th }}$ ed. Saunders Elsevier, Philadelphia, 2156p.

Rech R.R., Rissi D.R., Rodrigues A., Pierezan F., Piazer J.V.M., Kommers G.D. 
\& Barros C.S.L. 2006. Intoxicação por Solanum fastigiatum (Solanaceae) em bovinos: epidemiologia, sinais clínicos e morfometria das lesões cerebelares. Pesq. Vet. Bras. 26:183-189.

Riet-Correa F., Schild A.L. \& Fernandes C.G. 1998. Enfermidades do Sistema Nervoso dos Ruminantes no Sul do Rio Grande do Sul. Ciência Rural 28(2):341-348.

Schild A.L. 2001. Defeitos congênitos, p.20-43. In: Riet-Correa F., Schild A.L., Mendez M.C. \& Lemos R.A.A. (Eds), Doenças de Ruminantes e Eqüinos. Vol.1. 2 ${ }^{\mathrm{a}}$ ed. Livraria Varela, São Paulo. 425p.

Schild A.L., Riet-Correa F., Mendez M.C., Barros S.S. 1993. Hereditary hypermetria in Shorthorn cattle. J. Vet. Diagn. Invest. 5:640-642.

Schild A.L., Riet-Correa F., Portiansky E.L., Méndez M.C. \& Graça D.L. 2001.
Congenital cerebelar cortical degeneration in Holstein cattle in southern Brazil. Vet. Res. Commun. 25:189-195.

Stegelmeier B.L., James L.F., Panter K.E., Gardner D.R., Pfister J.A., Ralphs M.H. \& Molyneux R.J. 1999. Dose response of sheep poisoned with locoweed (Oxytropis sericea). J. Vet. Diagn. Invest. 11(5):448-456.

Tokarnia C.H., Döbereiner J. \& Canella C.F.C. 1960. Estudo experimental sobre a toxidez do "canudo" (Ipomoea fistulosa Mart.) em ruminantes. Arqs Inst. Biol. Animal, Rio de J., 3:59-71.

Summers B.A., Cummings J.F. \& De Lahunta A. 1995. Veterinary Neuropathology. Mosby, St Louis. 527p.

Underwood E.J. \& Suttle N.F. 1999. The Mineral Nutrition of Livestock. $3^{\text {rd }}$ ed. CABI, New York. 614p. 